\title{
Study of shock train/flame interaction and skin- friction reduction by hydrogen combustion in compressible boundary layer
}

\author{
Rui Xui ${ }^{a, b, *}$, Xing Zheng ${ }^{a}$, Lianjie Yue ${ }^{b}$, Shikong Zhang ${ }^{c}$, Chao Weng ${ }^{d}$ \\ a State Key Laboratory for Strength and Vibration of Mechanical Structures, Shaanxi Engineering Laboratory for \\ Vibration Control of Aerospace Structures, School of Aerospace, Xi'an Jiaotong University, 710049, Xi'an, People's \\ Republic of China \\ ${ }^{\mathrm{b}}$ State Key Laboratory of High Temperature Gas Dynamics, Institute of Mechanics, Chinese Academy of Sciences, \\ 100190, Beijing, China \\ ' Xi'an Modern Control Technology Research Institute, 710065, Xi'an, People's Republic of China \\ d Tongji University, 200092, Shanghai, People's Republic of China
}

\section{H I G H L I G H T S}

- Shock train/flame interaction and drag with boundary layer combustion are studied.

- Boundary layer separation is induced by the refracted shock waves from the flame.

- Both the skin friction and heat transfer increase with air/fuel temperature ratio.

- Skin friction is enhanced while heat transfer is unchanged as $\mathrm{C}_{\mathrm{H} 2 \mathrm{O}}$ increases.

- Changing air/fuel pressure ratio can affect both skin friction and heat transfer.

\section{A R T I C L E I N F O}

Article history:

Received 9 October 2019

Received in revised form

21 March 2020

Accepted 5 April 2020

Available online 29 April 2020

Keywords:

Compressible boundary layer

combustion

Skin-friction reduction

Shock train/flame interaction

\begin{abstract}
A B S T R A C T
A numerical study is carried out to investigate the shock train/flame interaction and skin friction with boundary layer combustion in compressible boundary layer. The Transition $k-k l-w$ model is employed as the turbulence model and the finite-rate model is selected as the combustion model. The results showed that the skin friction could be reduced by $50 \%$ through boundary layer combustion while the pure-mixing case can only bring about a $10 \%$ drag reduction. The ignition of hydrogen in the boundary layer leads to a rapid reduction in skin friction. When a shock wave intersects with the flame surface, in addition to the reflection, it is also refracted, which will cause the change of both skin friction and heat transfer to the wall. Studies on the effects of air/fuel temperature ratio reveal that both the skin friction and heat transfer increase with air/fuel temperature ratio. When the concentration of $\mathrm{H}_{2} \mathrm{O}$ increases in airflow, the skin friction is enhanced as the mixing and combustion between oxygen and hydrogen is suppressed with $\mathrm{H}_{2} \mathrm{O}$ addition. The results of changing the air/fuel pressure ratios show that at high airflow pressure, the distance between the flame and the wall is reduced, leading to increase of heat transfer to the wall.

๑ 2020 Hydrogen Energy Publications LLC. Published by Elsevier Ltd. All rights reserved.
\end{abstract}

\footnotetext{
* Corresponding author. State Key Laboratory for Strength and Vibration of Mechanical Structures, Shaanxi Engineering Laboratory for Vibration Control of Aerospace Structures, School of Aerospace, Xi'an Jiaotong University, 710049, Xi'an, People's Republic of China.

E-mail address: ruixue@xjtu.edu.cn (R. Xui).
} 


\section{Introduction}

Scramjet engines have been considered as one of the most appropriate propulsion systems for hypersonic air-breathing vehicles, and hence the development of scramjet engines attracts worldwide attention [1]. For hypersonic flight, the surface friction drag is the main source of the resistance. Investigations carried out by Anderson [2] showed that surface frictional resistance accounted for more than $50 \%$ of the high supersonic aircraft resistance. In addition, although the flow path of a scramjet engine is short relative to the whole hypersonic flight vehicle, experimental results carried out by Paull et al. [3] showed that the internal friction resistance in the engine including inlet, combustor and nozzle accounts for as much as $60 \%$ of the total friction resistance of the hypersonic vehicle. Therefore, it is of great significance to develop a technology to reduce the frictional resistance of scramjet engines, which can improve the whole hypersonic flight performance.

Generally, there are two main methodologies of drag reduction for an engine internal flow path, which are the passive drag reduction technique and the active drag reduction technique. Passive drag reduction methods, such as ribs [4], pits [5,6], convex hulls, etc. [7], which reduce the friction resistance through modifying the configuration of the wall surface, have been widely used in various fields. The disadvantage of this method is that the magnitude and the switch cannot be controlled during real operation. Plasma injection, wall film-injection, and boundary layer combustion, etc. [8-11] are active drag reduction methodologies which can be put into service as needed in flight. Previous studies have shown that about $8 \%$ of the drag reduction could be achieved through smooth internal flow surface design [3], and plasma injection drag reduction technology could provide about $20 \%$ of the average drag reduction rate [12]. However, Stalker's study [13] indicated that the surface friction resistance could be reduced by more than $50 \%$ through boundary layer combustion, which was 3 times the drag reduction rate of the wall film-injection technique in which no combustion exists. Moreover, relevant experiments were conducted in the T4 Stalker tube to study the effects of boundary layer combustion in actual combustor at the university of Queensland. The skin friction drag measured on the inner surface of the combustor indicated a reduction in skin friction drag of $30 \%$ when hydrogen burns in the boundary layer [14]. Therefore, compared with other drag reduction technologies, boundary layer combustion can achieve more reduction of skin friction and is ideal for combination with main fuel injections in scramjet engines.

The basic idea of drag reduction through boundary layer combustion is to inject fuel into boundary layer for ignition and combustion. Thus, the heat release in boundary layer would increase the temperature, which leads to a decrease in both the density of fluid and the Reynolds shear stress near the wall. Several studies have been carried out to investigate the effect of combustion or heat release on boundary layer and the underlying mechanism for skin-friction reduction. Larin et al. [15] conducted two-dimensional numerical simulations of turbulent boundary layer combustion, which proved that increasing the heat release in the boundary layer was beneficial to reduce the frictional resistance of the wall. Then Levin et al. [16] studied the quantitative relationship between the amount of heat input and the function of skin-friction reduction in the boundary layer under Mach 3 inflow condition to find the optimal heat release amount in boundary layer. Burtschell et al. [17] performed two-dimensional numerical simulations of boundary layer combustion under the influences of strong shock wave and found that the combustion of hydrogen in boundary layer not only reduced the frictional resistance of the wall, but also reduced the heat transfer rate to the wall as well. However, this study did not explain the reasons for the decrease in heat transfer rate.

Recently, Barth et al. [18] rederived the stalker's theoretical model and studied the skin-friction reduction mechanisms by boundary layer combustion using this theoretical model, they demonstrated that skin-friction reduction is accomplished through several coupled mechanisms: a change in near-wall viscosity, density changes and low-Reynolds stresses, and the low-momentum fuel stream thickens the boundary layer and changes the wall-normal velocity gradient. In 2014, Clark et al. [19] carried out numerical simulation of the heating plate under Mach 6 inflow condition by using SST k- $\omega$ turbulence model. They concluded that the main mechanism of drag reduction with boundary layer combustion was the change of the density distribution and the turbulent velocity fluctuations in boundary layer, which reduces the turbulent momentum transport of the free airflow to the wall and then leads to the surface friction resistance be decreased. The numerical simulation carried out by Gao et al. [20] showed that when the flame surface was near the edge of the boundary layer, the turbulent kinetic energy would be inhibited by the heat release, which causes both the heat transfer rate and the frictional resistance decrease. When the flame approached the wall, however, the heat transfer rate was sharply increased while the frictional resistance changes were not significant. In addition, based on their results and by integrating the Kármán momentum integral relation without local similarity hypothesis or changing Prandtl number, they improved the prediction theory for skin friction and heat transfers with boundary layer combustion. Edwards et al. [21] carried out Large-eddy/Reynolds-averaged Navier-Stokes (LES/RANS) simulation of the Burrows-Kurkov [22,23] supersonic reacting wall-jet experiment. The results showed that a lifted flame, which exhibited a transition from a partiallypremixed flame structure to a diffusion-flame structure, was formed in boundary layer and the combustion-induced volumetric expansion lead to thicken of the shear layer. Through Large Eddy Simulation (LES), Denman [24] investigated the turbulent transport process in boundary layer by adding a heat-release source. It was illustrated that the skin-friction reduction by heat addition in boundary layer was not caused only by the change of the density distribution within the boundary layer. The heat addition would increase the size of the near-wall vortex and decrease its frequency, which makes the near wall streaks increase their coherence length. Liu et al. [25] improved the skin-friction formula by directly integrating the $\mathrm{Ka}^{\prime} \mathrm{rma} \mathrm{n}$ momentum integral relation. The skin friction and heat transfer predicted by the improved theory were found to be better consistent with the experimental or 
numerical experimental data than the original theory established by Stalker. Recently, a numerical study conducted by Zhang et al. [26] showed that large skin-friction reduction could be obtained by boundary layer combustion, and further reduction could be achieved with adverse pressure gradient.

Therefore, though a large number of researches have been carried out on enhancing the efficiency of the supersonic combustion for elevating the thrust, available studies on the drag reduction of scramjet engines are relatively scarce. Therefore, in this study, the Transition $k-k l-w$ model is employed to investigate the shock/flame interaction and skin friction reduction in compressible boundary layer. Firstly, the numerical methods employed in this study are described and validated. Then, a typical configuration for boundary layer combustion flow is designed, and the shock train/flame interaction and the mechanisms of skin-friction reduction are analyzed. After that, the research on the effects of different conditions on boundary layer combustion are carried out to study the principal influencing factors for this promising dragreduction technology in scramjet engines.

\section{Computation methods and numerical validation}

\section{Models and numerical method}

The conservation form of the Reynolds-averaged NavierStokes equations with chemical reactions is given as follows:

$\frac{\partial}{\partial t} \oint_{\Omega} \vec{W} d \Omega+\oint_{\partial \Omega}(\vec{F}-\vec{G}) \cdot d \vec{S}=\oint_{\Omega} \vec{H} d \Omega$

where the conservative variable vector is defined as

$\vec{W}=\left(\rho \rho u \rho v \rho w \rho e \rho Y_{i}\right)$

$\vec{F}$ is inviscid vector fluxes, and $\vec{G}$ represents the item caused by the effects of viscosity, heat transport and component diffusion. $\vec{H}$ represents the chemical reaction source item. In Eq. (2), $\rho$ is the density, $u, v$ and $w$ are the velocity components in the $x, y$ and $z$ directions, respectively. $e$ is the total energy, and $Y_{i}$ is the mass fraction of species $i$.

In addition, for flow field of boundary layer, the phenomenon of boundary layer transition should be considered and modeled in numerical simulation. Compared to other turbulence models such as $k-\omega, k-\varepsilon$ models which do not take this phenomenon into account, Transition $k-k l-w$ model is a three-equation eddy-viscosity type, which includes transport equations for turbulent kinetic energy $\left(k_{T}\right)$, laminar kinetic energy $\left(k_{L}\right)$, and the inverse turbulent timescale $(\omega)$ for simulating the boundary layer transition process. Therefore, the Transition $k-k l-w$ model is employed in this study.

Chemical source terms are calculated directly using finiterate chemistry model with a reduced chemistry mechanism. As shown in Table 1 , a nine-species $\left(\mathrm{H}_{2} \mathrm{H} \mathrm{O}_{2} \mathrm{O} \mathrm{OH} \mathrm{HO} \mathrm{H}_{2} \mathrm{H}_{2} \mathrm{O}_{2}\right.$ $\mathrm{H}_{2} \mathrm{O} \mathrm{N}$ ), twenty-seven-reaction model established by Marinov [27] is adopted as the hydrogen/air reaction mechanism in the following numerical simulations, which has been fairly well established and is widely used for hydrogen-air combustion investigation [28]. This reaction mechanism was adequately compared with the detailed chemical kinetics. It showed that it could accurately simulate the ignition delay time of hydrogen combustion and effectively capture the effects of changes in airflow components, which is quite important in this study. The reaction rate constants are approximated by the Arrhenius Equation (3):

$k=A T^{B} \exp (-E / R T)$

where $\mathrm{A}$ is the pre-exponential collision frequency factor, $\mathrm{T}$ represents the temperature and $B$ means the temperature exponent, $\mathrm{E}$ is the activation energy, and $\mathrm{R}$ represents the gas constant.

For the numerical scheme, the Advection Upstream Splitting Method (AUSM) [29], which allows for exact resolution of contact and shock discontinuities is employed for discretizing the inviscid flux vectors. The Third-Oder Monotone Upstream-Centered Scheme (MUSCL) [30] was used for spatial discretization of the scalars. The MUSCL scheme blends a central differencing scheme and a second-order upwind

Table 1 - Rate constants for 9 species 27-step chemical kinetics of hydrogen [27].

\begin{tabular}{|c|c|c|c|}
\hline Reaction & A & B & E \\
\hline $\mathrm{OH}+\mathrm{H}_{2}=\mathrm{H}+\mathrm{H}_{2} \mathrm{O}$ & $2.14 \mathrm{E}+08$ & 1.52 & 3449 \\
\hline $\mathrm{O}+\mathrm{OH}=\mathrm{O}_{2}+\mathrm{H}$ & $2.02 \mathrm{E}+14$ & -0.4 & 0 \\
\hline $\mathrm{O}+\mathrm{H}_{2}=\mathrm{OH}+\mathrm{H}$ & $5.06 \mathrm{E}+04$ & 2.67 & 6290 \\
\hline $\mathrm{H}+\mathrm{O}_{2}(+\mathrm{M})=\mathrm{HO}_{2}(+\mathrm{M})$ & $4.52 \mathrm{E}+13$ & 0 & 0 \\
\hline LOW/1.05E $+19-1.2570 .0 /$ & & & \\
\hline $\mathrm{H}_{2} \mathrm{O} / 0.0 / \mathrm{H}_{2} / 0.0 / \mathrm{N}_{2} / 0.0 /$ & & & \\
\hline $\begin{array}{l}\mathrm{H}+\mathrm{O}_{2}\left(+\mathrm{N}_{2}\right)=\mathrm{HO}_{2}\left(+\mathrm{N}_{2}\right) \\
\mathrm{LOW} / 2.03 \mathrm{E}+20-1.590 .0 /\end{array}$ & $4.52 \mathrm{E}+13$ & 0 & 0 \\
\hline $\begin{array}{l}\mathrm{H}+\mathrm{O}_{2}\left(+\mathrm{H}_{2}\right)=\mathrm{HO}_{2}\left(+\mathrm{H}_{2}\right) \\
\text { LOW/1.52E }+19-1.1330 .0 /\end{array}$ & $4.52 \mathrm{E}+13$ & 0 & 0 \\
\hline $\begin{array}{l}\mathrm{H}+\mathrm{O}_{2}\left(+\mathrm{H}_{2} \mathrm{O}\right)=\mathrm{HO}_{2}\left(+\mathrm{H}_{2} \mathrm{O}\right) \\
\mathrm{LOW} / 2.10 \mathrm{E}+23-2.4370 .0 /\end{array}$ & $4.52 \mathrm{E}+13$ & 0 & 0 \\
\hline $\mathrm{OH}+\mathrm{HO}_{2}=\mathrm{H}_{2} \mathrm{O}+\mathrm{O}_{2}$ & $2.13 \mathrm{E}+28$ & -4.827 & 3500 \\
\hline $\begin{array}{l}\mathrm{OH}+\mathrm{HO}_{2}=\mathrm{H}_{2} \mathrm{O}+\mathrm{O}_{2} \\
\text { DUP }\end{array}$ & $9.10 \mathrm{E}+14$ & 0 & 10964 \\
\hline $\begin{array}{l}\mathrm{H}+\mathrm{HO}_{2}=\mathrm{OH}+\mathrm{OH} \\
\text { DUP }\end{array}$ & $1.50 \mathrm{E}+14$ & 0 & 1000 \\
\hline $\mathrm{H}+\mathrm{HO}_{2}=\mathrm{H}_{2}+\mathrm{O}_{2}$ & $8.45 \mathrm{E}+11$ & 0.65 & 1241 \\
\hline $\mathrm{H}+\mathrm{HO}_{2}=\mathrm{O}+\mathrm{H} 2 \mathrm{O}$ & $3.01 \mathrm{E}+13$ & 0 & 1721 \\
\hline $\mathrm{O}+\mathrm{HO}_{2}=\mathrm{O}_{2}+\mathrm{OH}$ & $3.25 \mathrm{E}+13$ & 0 & 0 \\
\hline $\mathrm{OH}+\mathrm{OH}=\mathrm{O}+\mathrm{H}_{2} \mathrm{O}$ & $3.57 \mathrm{E}+04$ & 2.4 & -2112 \\
\hline $\mathrm{H}+\mathrm{H}+\mathrm{M}=\mathrm{H}_{2}+\mathrm{M}$ & $1.00 \mathrm{E}+18$ & -1 & 0 \\
\hline $\mathrm{H}_{2} \mathrm{O} / 0.0 / \mathrm{H}_{2} / 0.0 /$ & & & \\
\hline $\mathrm{H}+\mathrm{H}+\mathrm{H}_{2}=\mathrm{H}_{2}+\mathrm{H}_{2}$ & $9.20 \mathrm{E}+16$ & -0.6 & 0 \\
\hline $\mathrm{H}+\mathrm{H}+\mathrm{H}_{2} \mathrm{O}=\mathrm{H}_{2}+\mathrm{H}_{2} \mathrm{O}$ & $6.00 \mathrm{E}+19$ & -1.25 & 0 \\
\hline $\begin{array}{l}\mathrm{H}+\mathrm{OH}+\mathrm{M}=\mathrm{H}_{2} \mathrm{O}+\mathrm{M} \\
\mathrm{H}_{2} \mathrm{O} / 6.4 /\end{array}$ & $2.21 \mathrm{E}+22$ & -2 & 0 \\
\hline $\begin{array}{l}\mathrm{H}+\mathrm{O}+\mathrm{M}=\mathrm{OH}+\mathrm{M} \\
\mathrm{H}_{2} \mathrm{O} / 6.4 /\end{array}$ & $4.71 \mathrm{E}+18$ & -1 & 0 \\
\hline $\mathrm{O}+\mathrm{O}+\mathrm{M}=\mathrm{O}_{2}+\mathrm{M}$ & $1.89 \mathrm{E}+13$ & 0 & -1788 \\
\hline $\begin{array}{l}\mathrm{HO}_{2}+\mathrm{HO}_{2}=\mathrm{H}_{2} \mathrm{O}_{2}+\mathrm{O}_{2} \\
\text { DUP }\end{array}$ & $4.20 \mathrm{E}+14$ & 0 & 11982 \\
\hline $\begin{array}{l}\mathrm{HO}_{2}+\mathrm{HO}_{2}=\mathrm{H}_{2} \mathrm{O}_{2}+\mathrm{O}_{2} \\
\text { DUP }\end{array}$ & $1.30 \mathrm{E}+11$ & 0 & -1629 \\
\hline $\begin{array}{l}\mathrm{OH}+\mathrm{OH}(+\mathrm{M})=\mathrm{H}_{2} \mathrm{O}_{2}(+\mathrm{M}) \\
\mathrm{LOW} / 3.04 \mathrm{E}+30-4.632049 .0 /\end{array}$ & $1.24 \mathrm{E}+14$ & -0.37 & 0 \\
\hline TROE/0.470 100.0 2000.0 1.0E+15/ & & & \\
\hline $\mathrm{H}_{2} \mathrm{O}_{2}+\mathrm{H}=\mathrm{HO}_{2}+\mathrm{H}_{2}$ & $1.98 \mathrm{E}+06$ & 2 & 2435 \\
\hline $\mathrm{H}_{2} \mathrm{O}_{2}+\mathrm{H}=\mathrm{OH}+\mathrm{H}_{2} \mathrm{O}$ & $3.07 \mathrm{E}+13$ & 0 & 4217 \\
\hline $\mathrm{H}_{2} \mathrm{O}_{2}+\mathrm{O}=\mathrm{OH}+\mathrm{HO}_{2}$ & $9.55 \mathrm{E}+06$ & 2 & 3970 \\
\hline $\mathrm{H}_{2} \mathrm{O}_{2}+\mathrm{OH}=\mathrm{H}_{2} \mathrm{O}+\mathrm{HO}_{2}$ & $2.40 \mathrm{E}+00$ & 4.042 & -2162 \\
\hline
\end{tabular}


scheme, providing the potential to improve spatial accuracy and reduce numerical diffusion. The least squares cell based method was selected to compute the gradients because it is the least computationally expensive method offered.

\section{Validation of the numerical simulation method}

As the configuration of the wall-jet combustion experiment conducted by Burrows and Kurkov [23,24] is quite similar to the form which is required for boundary layer combustion, it is chosen to validate the adopted simulation method. This experimental database is quite extensive, which includes the data of Pitot pressure and stagnation temperature, gassampling mole fraction measurements, and ignition onset locations (obtained from ultraviolet imaging) [31-35]. Thus, it is a good choice for the validation of numerical methods in this study.

The scheme of the experimental configuration is shown in Fig. 1. The height of the airstream entrance is $89 \mathrm{~mm}$. Hydrogen is injected parallel to the airstream from a slot installed after the backward step with a height of $4 \mathrm{~mm}[23,24]$. After that, the wall at the hydrogen injecting side expands, making the whole height of the section increase linearly from $93.8 \mathrm{~mm}$ to $104.8 \mathrm{~mm}$.

The two-dimensional computational structured mesh is shown in Fig. 2. Meshes in domains around the wall and near the mixing layer are refined. The height of the first row of cells is set at a distance of $10^{-5} \mathrm{~m}$ for the walls and the total number of cells is 128 520. As the geometry of the wind tunnel of Burrows-Kurkov experiments that provides the air to the combustor section is not given in public domains, in order to satisfy the requirement of boundary layer thickness of airstream, the computation domain was extended about 7 times of the entrance height upstream of the entrance to let the airflow boundary layer grow. Thus, an appropriate thickness of boundary layer could be formed to simulate the airflow entrance condition in experiments. The airstream and fuel injection conditions for both the pure-mixing and the combustion cases are illustrated in Table 2. It is noted that no oxygen exists in the airstream for the pure-mixing case to guarantee no combustion take place.

For the wall, the no-slip conditions are assumed and the wall temperature is kept at $T_{\mathrm{W}}=300 \mathrm{~K}$. At the outflow, all the physical variables are extrapolated from the internal cells due to the flow being supersonic. Various key parameters were monitored to determine the convergence, namely: 1) The steady-state residual error should be 3 to 4 orders of magnitude smaller than the initial value. 2) The time history of water

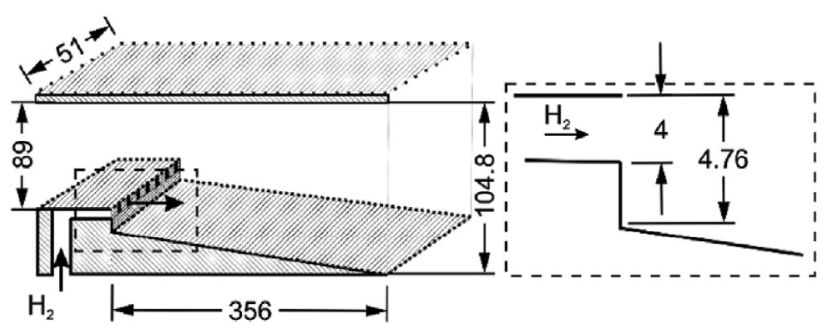

Fig. 1 - Schematic of Burrows and Kurkov combustor [36].

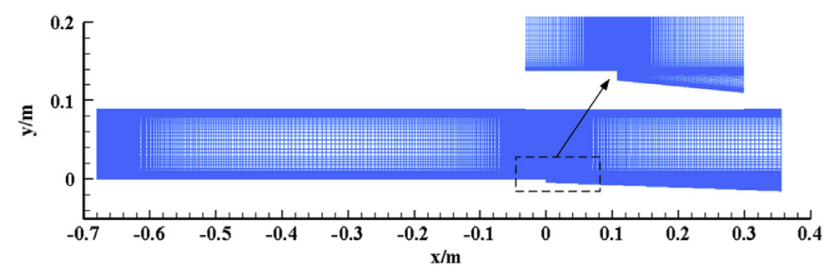

Fig. 2 - The computational grids of the configuration.

mass flux at the exit plane should remain unchanged. 3) The relative mass flow rate error, $\left|\dot{m}_{\text {out }}-\dot{m}_{\text {in }}\right| / \dot{m}_{\text {in }}$, was on the order of $10^{-7}$.

Fig. 3 shows the comparison of the computational mole fraction distributions for different species at the exit with the experimental data for pure-mixing case, in which the coordinate y represents the distance away from the wall. It can be seen that the computational results for mole fraction distributions of $\mathrm{H}_{2}, \mathrm{H}_{2} \mathrm{O}$, and $\mathrm{N}_{2}$ agree fairly well with the experimental data. Therefore, the mixing between fuel and airflow, and the boundary layer development process could be accurately captured by the Transition $k-k l-w$ model employed in this study.

For the combustion case, the hydrogen injection condition is kept the same while the airstream temperature is increased and oxygen is added. The total temperature distribution at $\mathrm{x}=0 \mathrm{~m}$, which could be used to indicate the boundary layer thickness for airflow inlet, is shown in Fig. 4. The reference temperature $\left(\mathrm{T}_{\text {ref }}\right)$ in Fig. 4 is $2830 \mathrm{~K}$. Also, good agreement is achieved between the computational results and experimental data, and the growth of boundary layer upstream is appropriate to simulate the thickness of boundary layer at the entrance $(\mathrm{x}=0 \mathrm{~m})$.

Figs. 5 and 6 show the temperature and the distribution of species mole fraction at the exit respectively. From Fig. 5, it could be seen that compared to results obtained by Gao et al. [20] with $\mathrm{k}-\mathrm{w}$ SST model, both the thickness and the position of the flame are more accurate in this simulation. However, the maximum temperature is slightly lower than the experimental data. Furthermore, the temperature and $\mathrm{OH}$ mass fraction contours are illustrated in Fig. 7 and Fig. 8. It can be seen that the self-ignition position is near $\mathrm{x}=0.12 \mathrm{~m}$, which is quite close to the experimental results. Therefore, the comparisons between the computational and experimental results above illustrate that the numerical simulations can well reproduce the boundary layer mixing and combustion revealed by the experimental data. Consequently, the numerical simulation approach adopted in this paper is reliable and can be adequate enough to investigate the boundary layer combustion flows.

\section{Analysis and discussion}

In order to investigate the effect of different airflow factors on boundary layer combustion, a configuration which is similar to the flow model proposed by Stalker [13] is designed for numerical experiments. As shown in Fig. 9, hydrogen is injected parallel to the airstream from a slot installed after the backward step at the height $\mathrm{h}=4 \mathrm{~mm}$. Then a flat-plate 
Table 2 - Inflow conditions for the airstream and injected fuel [23,24].

\begin{tabular}{lllllll}
\hline Parameter & \multicolumn{1}{c}{$\mathrm{Ma}$} & $\mathrm{T} / \mathrm{K}$ & $\mathrm{P} / \mathrm{kPa}$ & $\mathrm{Y}_{\mathrm{O} 2}$ & $\mathrm{Y}_{\mathrm{H} 2}$ & $\mathrm{Y}_{\mathrm{N} 2}$ \\
\hline & Pure-mixing & & & & & \\
Air & 2.44 & 1150 & 96 & 0 & 0 & 0.768 \\
Hydrogen Injection & 1.0 & 254 & 100 & 0 & 1 & 0 \\
Air & Combustion & & & & 0.232 \\
Hydrogen Injection & 2.44 & 1270 & 96 & 0.258 & 0 & 0.486 \\
\hline
\end{tabular}

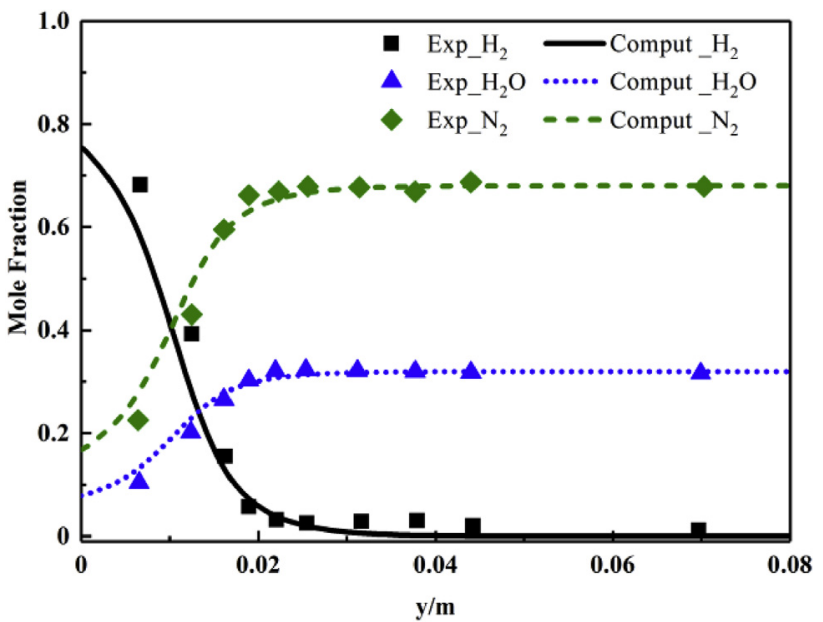

Fig. 3 - Pure-mixing case: distribution of species mole fraction at exit.

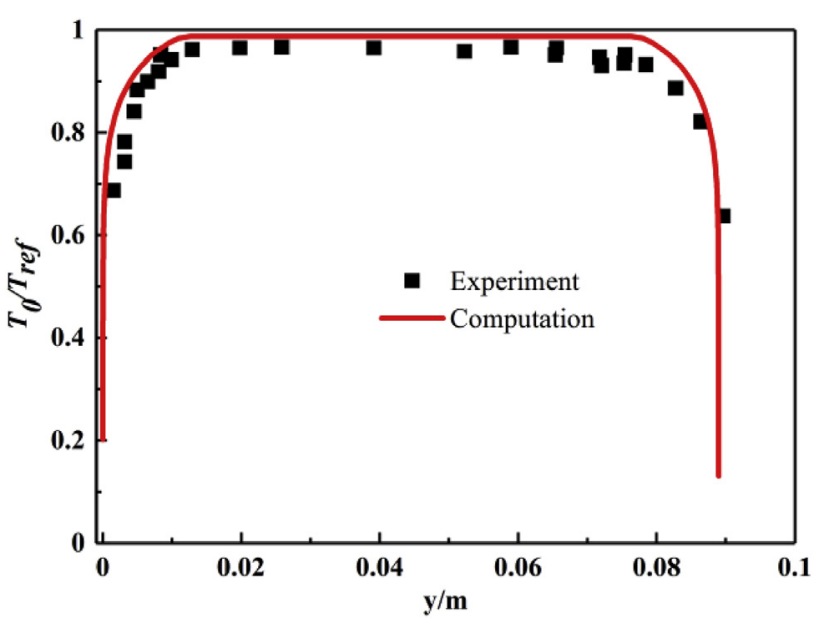

Fig. 4 - Combustion case: total temperature distribution at $\mathbf{x}=\mathbf{0} \mathbf{m}$

boundary layer flow forms and the non-premixed combustion occurs at some distance downstream. The wall at the hydrogen injecting side is straight and extends to $1500 \mathrm{~mm}$ from the fuel injection. Notably, not like injection fuel mixing and combustion to produce thrust in scramjet combustor, the slot in this situation is established to inject fuel into boundary layer, so it is not like the traditional injector. In actual scramjet engine, the $\mathrm{H}_{2}$ fuel injected from a slot is not the main fuel, but is intended to reduce the skin friction on purpose.

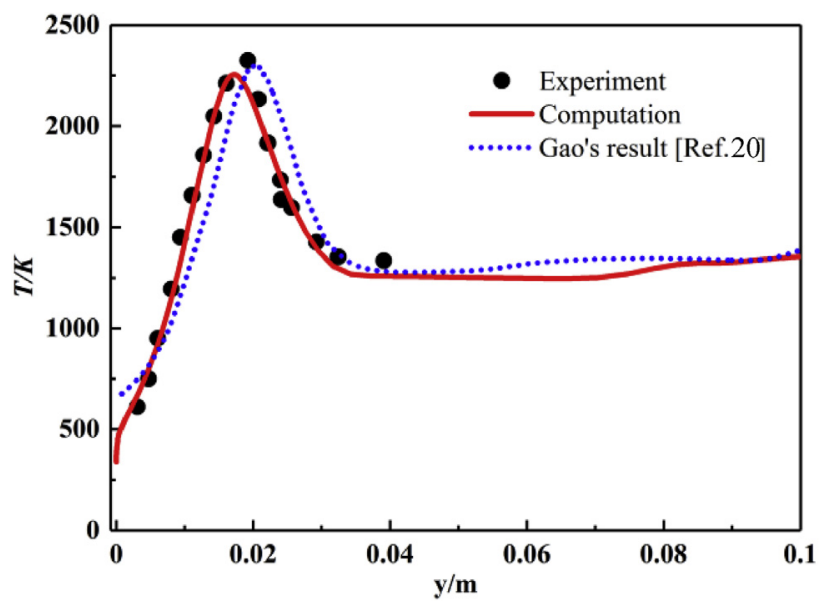

Fig. 5 - Combustion case: temperature distribution at the exit.

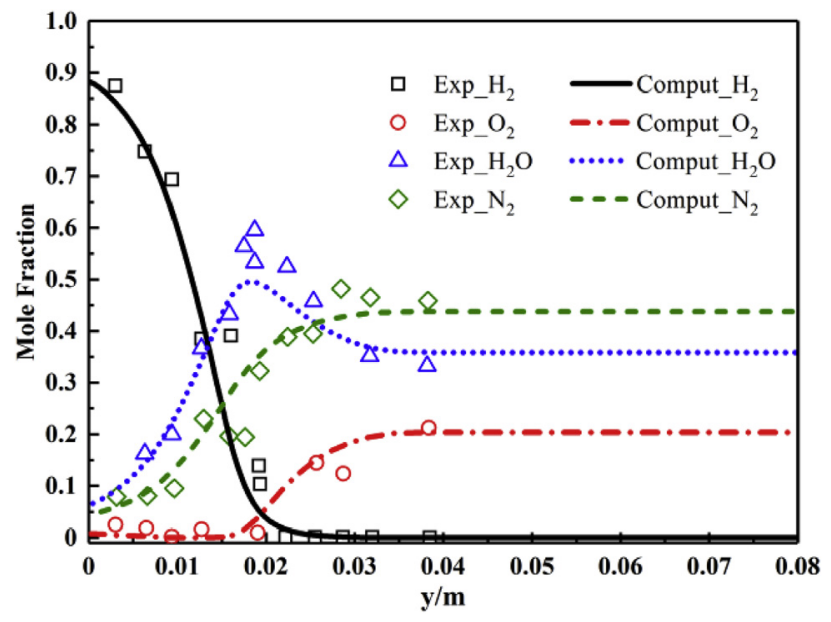

Fig. 6 - Combustion case: distribution of species mole fraction at exit.

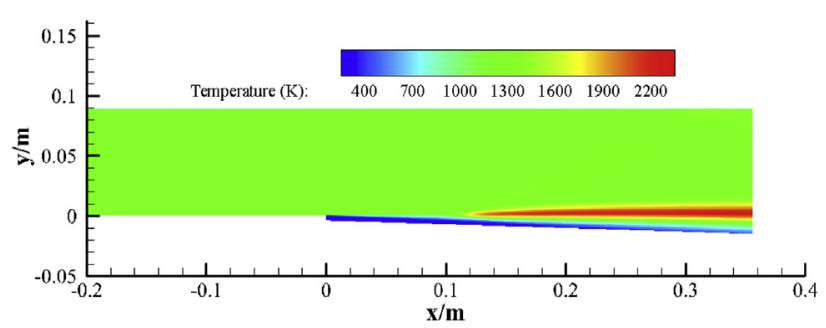

Fig. 7 - Combustion case: temperature contour. 


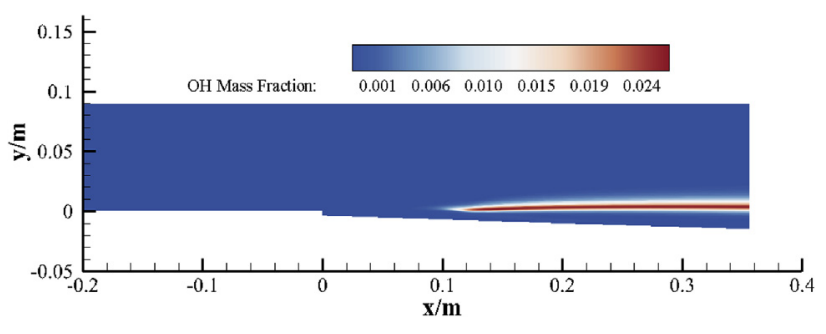

Fig. 8 - Combustion case: OH mass fraction contour.

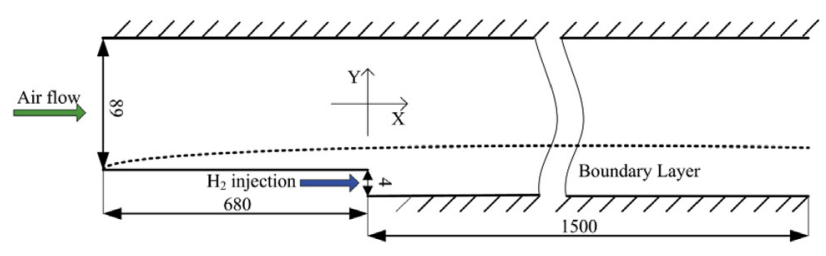

Fig. 9 - Configuration of numerical experiment.

As shown in Table 3, the cases that will be presented and discussed are constituted of a variation of the air inlet conditions such as static temperature, $\mathrm{T}_{\text {air }}$, inlet $\mathrm{H}_{2} \mathrm{O}$ mole fraction, $\mathrm{C}_{\mathrm{H} 2 \mathrm{O}}$, and static pressure, $\mathrm{P}_{\text {air }}$.

Three different grids are selected for grid independent verification. The grid information is shown in Table $4 . \mathrm{N}$ and $\mathrm{y}_{1}$ in the table represents the number of grid cells and the height of the first layer grid, respectively.

The temperature distribution at exit and the mass fraction of $\mathrm{H}_{2}$ along the down wall are shown in Fig. 10. It can be seen that the temperature distribution at the exit does not exhibit any major difference by employing these three mesh scales. For the results of species distribution like $\mathrm{H}_{2}$, compared to medium and fine scale, there is a large difference at $\mathrm{x}=0.45 \mathrm{~m}$ (nearly 13\%). However, there is good agreement between the medium and fine grids. It is clear that the variation of grid scale has great influence on results in the region near the wall. Hence, a medium grid is adopted in the subsequent numerical analysis, the final mesh contains 306453 structured grid.

\section{Influence of boundary-layer combustion on skin friction and heat transfer}

For the compressible turbulent boundary layer, Van Driest proposed a correlation for predicting skin friction with widely varying boundary-layer density distributions as the following [12]:

$4.15 \log _{10}\left(R_{e x} C_{f} \mu_{e} / \mu_{s}\right)+1.7=F_{0}\left[C_{f}\left(T_{a w}-T_{e}\right) / T_{e}\right]^{-\frac{1}{2}}$

The subscript $e$ and $w$ represents the mainstream and surface, respectively, $R_{e x}$ represents the Reynolds number
Table 4 - Meshes used to verify the grid independence.

\begin{tabular}{llll} 
Name & Coarse & Medium & Fine \\
\hline $\mathrm{N}$ & 45023 & 306453 & 403123 \\
$\mathrm{y}+$ & 3 & 1 & 1 \\
$\mathrm{y}_{1}$ & $10^{-5}$ & $10^{-6}$ & $10^{-6}$ \\
\hline
\end{tabular}

along the flow path, $\mu_{e}$ is the mainstream molecular viscosity, $\mu_{\mathrm{s}}$ is the wall molecular viscosity and $\mathrm{T}_{a w}$ is the wall adiabatic temperature. $F_{0}$ is expressed as

$F_{0}=\sin ^{-1}\left[\left(2 a^{2}-b\right) / Q\right]+\sin ^{-1}\left(\frac{b}{Q}\right)$

The expressions of $a$ and $b$ are

$a^{2}=\frac{u^{2}}{2 H_{w}}$

$\mathrm{b}=\left(\mathrm{H}_{e}-\mathrm{H}_{w}\right) / \mathrm{H}_{w}$

$Q=\left(b^{2}+4 a^{2}\right)^{\frac{1}{2}}$

In order to verify the accuracy of the adopted turbulence model for skin-friction prediction, a case without hydrogen injection under the conditions given in Table 1 is first simulated, and the obtained distributions of skin-friction coefficient is depicted in Fig. 11, together with the Van Driest II correlation results. Good agreement can be seen regarding the skin-friction coefficient, which further indicates that the numerical model employed in this study is reliable and hence can be used for further research.

Fig. 12 shows the influences of the boundary layer mixing and combustion on the skin-friction coefficient with respect to the no-injection value at baseline condition (BSL), where $C_{f, \text { mix }}, C_{f, \text { com }}$ and $C_{f, \text { no-injection }}$ represent the skin friction coefficient at the pure-mixing, combustion and no fuel injecting conditions. In the near field directly behind the injector, the injection of hydrogen into boundary layer made the wall friction rapidly reduce. This is due to the fact that both the density and the velocity of hydrogen are less than that of the air inflow, thus, the injection of hydrogen in boundary layer will lead to the density gradient and the corresponding wall shear force largely decrease.

In the vicinity of $\mathrm{x} \approx 0.12 \mathrm{~m}$, the skin-friction for the combustion case decreases rapidly in Fig. 12 to reach the value of near zero, which means almost no skin friction exist at this position. Actually, in Fig. 17(a), it is known that this position is the self-ignition position for combustion case. After that, as turbulent mixing occur between the airflow and boundary layer, the skin friction increases for both pure-mixing and combustion cases. Consequently, the skin-friction coefficient

Table 3 - Numerical experimental items for Baseline and Cases 1-6.

\begin{tabular}{llllllcc} 
Parameters & BSL & Case1 & Case2 & Case3 & Case4 & Case5 & Case6 \\
\hline Ma & 2.44 & 2.44 & 2.44 & 2.44 & 2.44 & 2.44 & 2.44 \\
T(K) & 1270 & 1143 & 1397 & 1270 & 1270 & 1270 & 1270 \\
P(MPa $)$ & 0.1 & 0.1 & 0.1 & 0.1 & 0.1 & 0.09 & 0.11 \\
$\mathrm{C}_{\mathrm{H} 2 \mathrm{O}}$ & 0.256 & 0.256 & 0.256 & 0.2048 & 0.3072 & 0.256 & 0.256 \\
\hline
\end{tabular}




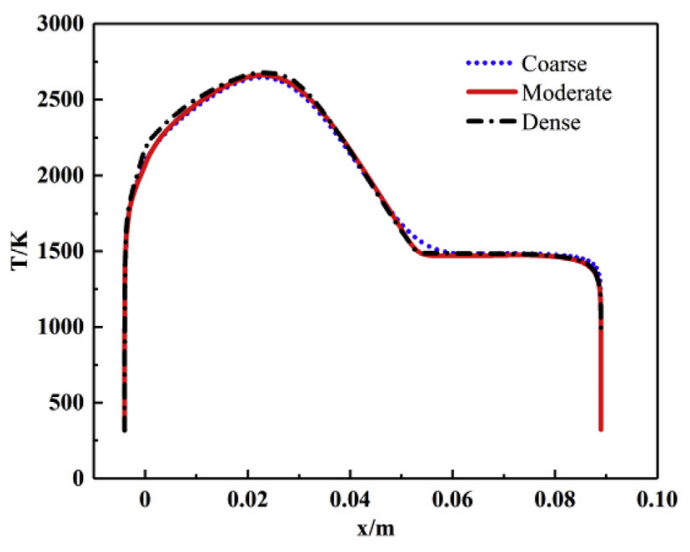

(a)

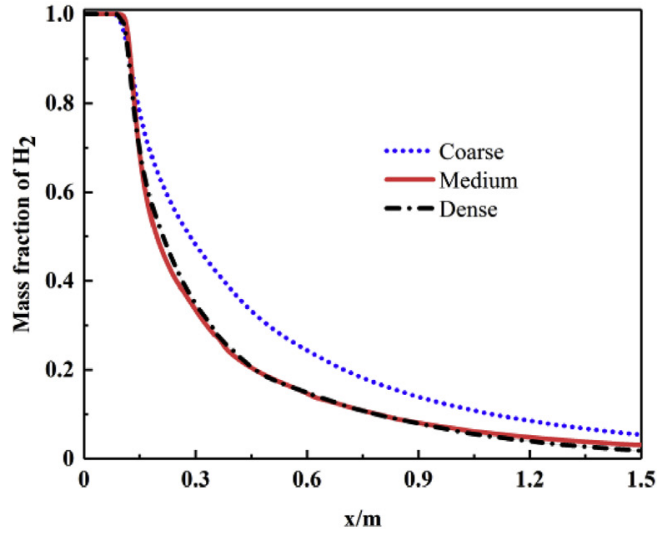

(b)

Fig. 10 - Temperature distribution (a) and Mass fraction of $\mathrm{H}_{2}$ (b) of three grid solutions.

ratio is stable at about 0.9 (10\% reduction) for the pure-mixing case, while for the combustion case, the value stays around about 0.5 (50\% reduction) until the exit at $\mathrm{x}=1.5 \mathrm{~m}$. The cause of fluctuation in skin friction coefficient for combustion case is due to the interaction between the shock train and the flame. Therefore, it is obvious that boundary layer combustion is effective for skin friction reduction in supersonic flows.

Based on the definition of shear stress $\tau=\mu \frac{\partial u}{\partial y}$, it is worthwhile to study the mechanism of skin-friction reduction with combustion. As shown in Fig. 13 (a), the molecular viscosity for both cases are almost the same in $0<\mathrm{x}<0.2 \mathrm{~m}$ as the primary species is hydrogen near the wall. The 'depression' for the velocity gradient shown in Fig. 13 (b) illustrates that the change of skin friction in the near field around the injector is mainly caused by the velocity variation normal to the wall.

In addition, as shown in Fig. 14, the heat release induced by combustion can make the density of the gas in the boundary layer reduce. Meanwhile, the thickness of boundary layer has been increased, which can result in the reduction in vertical velocity gradient.

As combustion occurs in the boundary layer, it is logically to assume that the heat transfer to the wall will be increased.

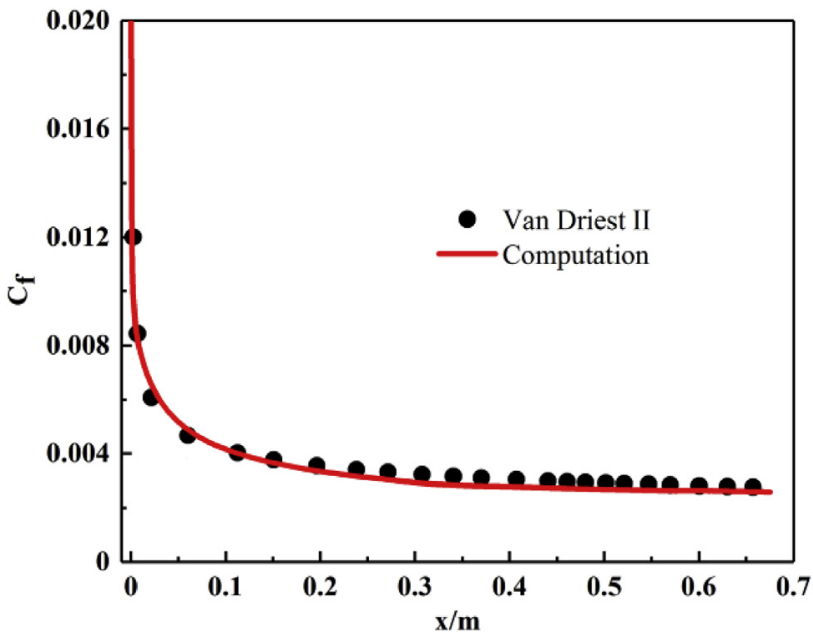

Fig. 11 - Distributions of $C_{f}$ for no- $\mathrm{H}_{2}$-injection case.
Therefore, the effect of boundary layer combustion on the wall heat transfer is extracted and shown in Fig. 15. $C_{h \text {,com }}$, $\mathrm{C}_{h \text {,mix }}$ and $\mathrm{C}_{h \text {,no-injection }}$ are the Stanton numbers for combustion, pure-mixing and no-injection cases. It can be seen that from $\mathrm{x}=0$ to $\mathrm{x}=0.6 \mathrm{~m}$, the ratios of the Stanton number are almost the same for both combustion and pure-mixing conditions. The reason for this is that in this region, though selfignition occurs near $\mathrm{x}=0.12 \mathrm{~m}$, the main component of the gas close to the wall is hydrogen. Thus, the wall jet cooling effect plays a leading role within this region, which could reduce the heat transfer more than 50\%. Downstream $\mathrm{x}=0.6 \mathrm{~m}$, as the diffusion and turbulent transport of the heat release produced by combustion to the wall, the heat transfer coefficient increased at a larger speed for combustion case. Until $\mathrm{x} \approx 1.2 \mathrm{~m}$, the heat transfer coefficient is the same as that of the no-injection condition. After that, the heat transfer rate is higher for the combustion case than that for the noinjection case and the largest increase along the flow path is about $20 \%$. Therefore, it can be seen that even with the addition of boundary layer combustion, the heat transfer is reduced for most of the length of the flow path (about $80 \%$ length) compared to no-injection case, which agrees with the

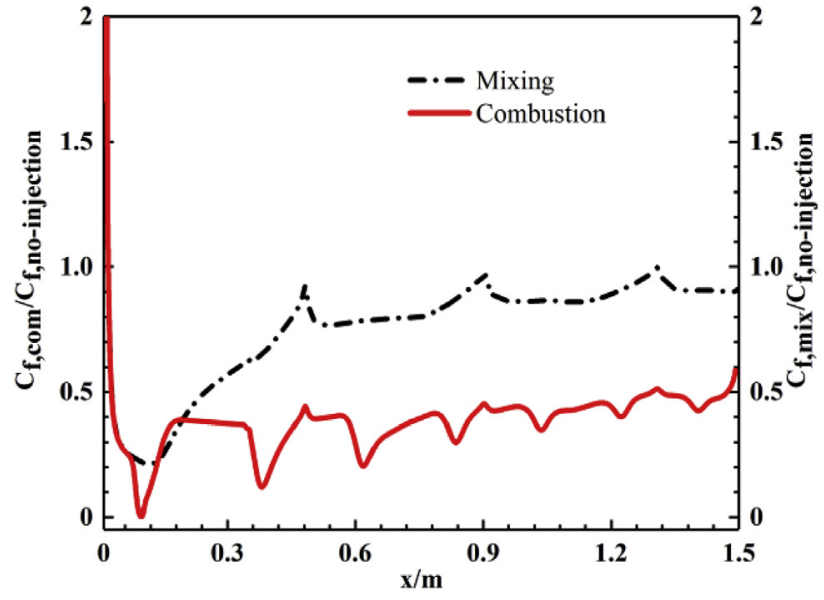

Fig. 12 - Influences on $C_{\mathrm{f}}$ by boundary-layer mixing and combustion. 


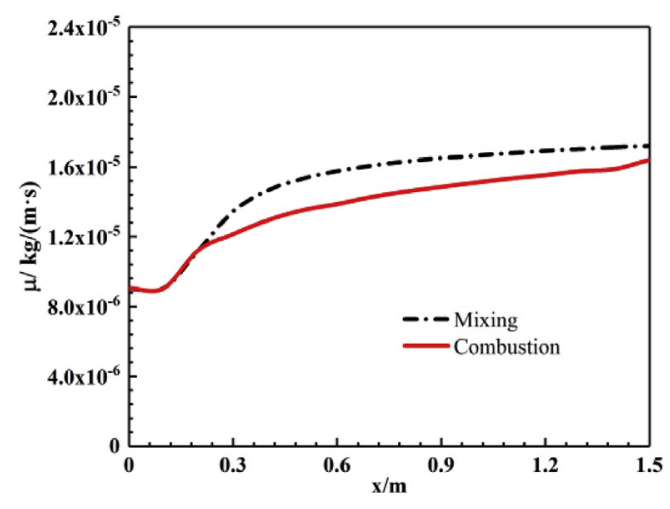

(a)

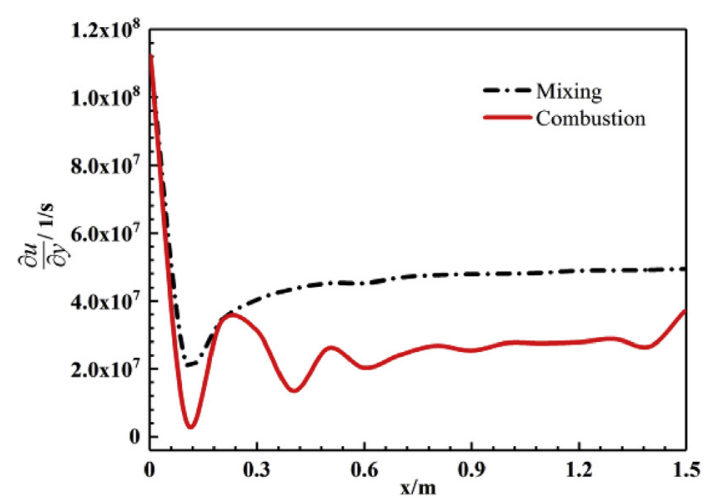

(b)

Fig. 13 - Profiles of viscosity coefficient (a) and velocity gradient (b) along the bottom wall.

measured results of the heat transfer in Ref. [37]. If the length of the wall is less than $1.2 \mathrm{~m}$, the boundary layer combustion could achieve the reduction for both skin friction and heat transfer on the wall.

\section{Influence of the air/fuel temperature ratio}

After analyzing the characteristics and the mechanism of the skin friction and heat transfer for boundary layer combustion, the influence of different factors on boundary combustion will be studied. Firstly, the effect of temperature ratio is investigated. For the BSL, the air inflow temperature is $\mathrm{T}_{\text {air }}=1270 \mathrm{~K}$ and the corresponding air/fuel temperature ratio is $R_{\text {Tair/Tfuel- }}$ $=5$. To investigate the influence of different air/fuel temperature ratios, the air inflow temperature is then modified to $\mathrm{T}_{\text {in }}=1397 \mathrm{~K}$ and $1143 \mathrm{~K}$ (temperature ratio $\mathrm{R}_{\text {Tair/Tfuel }}=5.5$ and 4.5) respectively while other boundary conditions are kept the same.

The static pressure and Mach number contours for different $\mathrm{T}_{\text {air }} / \mathrm{T}_{\text {fuel }}$ ratios are presented in Fig. 16(a) and (b) respectively. For all the three cases, due to the sudden expansion of the flow area at the fuel injector, an expansion wave is generated. A shock wave is produced at the

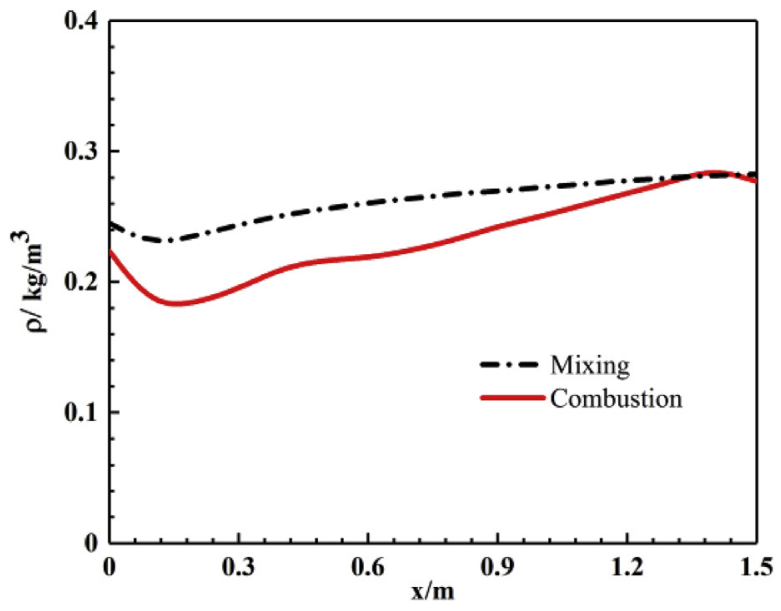

Fig. 14 - Influences on density between pure-mixing and combustion cases. corresponding ignition position and it is then continuously reflected between the upper wall and the flame, leading the formation of a shock train. When the reflected shock waves from the upper wall intersect with the flame surface, in addition to the reflection, they are also refracted inside the flame and go through the flow on lower wall.

The temperature contours for the three cases are presented in Fig. 17(a). For all these three cases, fuel is autoignited at some distance downstream of the fuel injection port. The solid black line in Fig. 17(a) represents the edge of the flame where the temperature is $1700 \mathrm{~K}$ and it is obvious that a lifted non-premixed flame is formed in boundary layer combustion. When the temperature ratio is $\mathrm{T}_{\text {air }} / \mathrm{T}_{\text {fuel }}=4.5$, the ignition occurs at about $\mathrm{x}=0.22 \mathrm{~m}$ and as the temperature ratio increases, the self-ignition position moves upstream. Until the ratio increases to $\mathrm{T}_{\text {air }} / \mathrm{T}_{\text {fuel }}=5.5$, the ignition starts immediately after the fuel inlet at about $\mathrm{x}=0.05 \mathrm{~m}$. This is due to the fact that as the inlet pressure and Mach number of the airflow remain unchanged, the decrease of airflow temperature would lead the total mass flow rate increase, which means the equivalence ratio will be decreased. Thus, together with the temperature drop, the self-ignition position will move downstream.

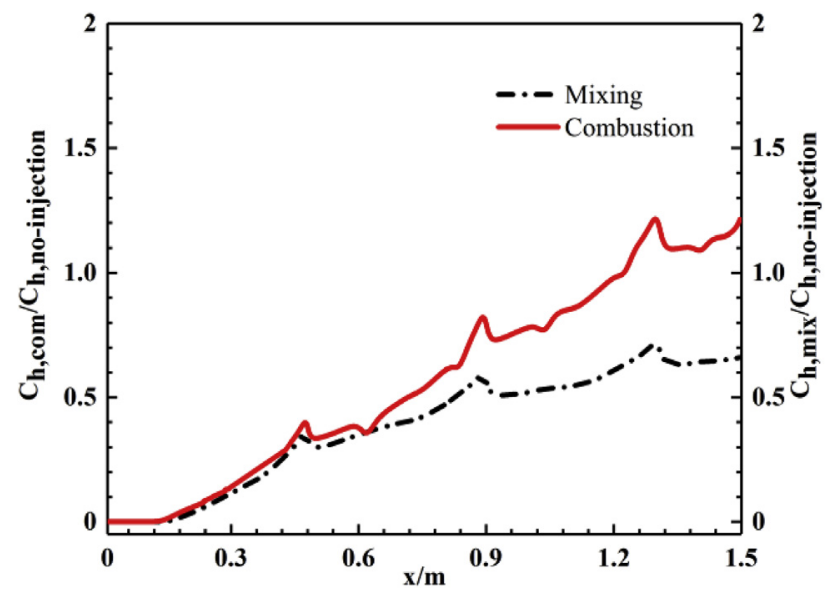

Fig. 15 - Influences on $C_{h}$ between pure-mixing and combustion cases. 

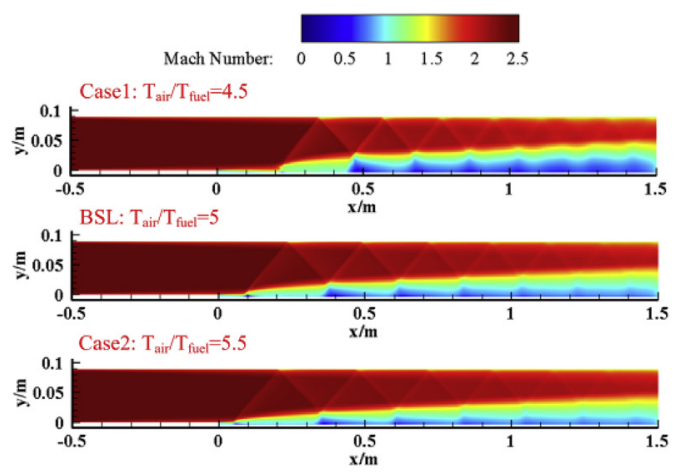

(a)

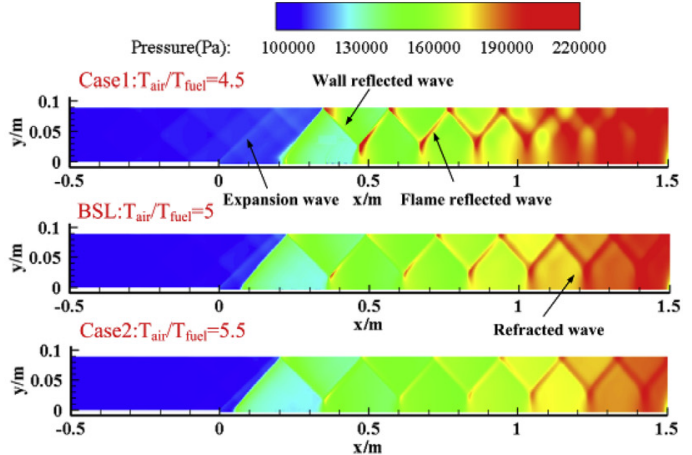

(b)

Fig. 16 - Pressure (a) and Mach number (b) contours for different temperature ratios.

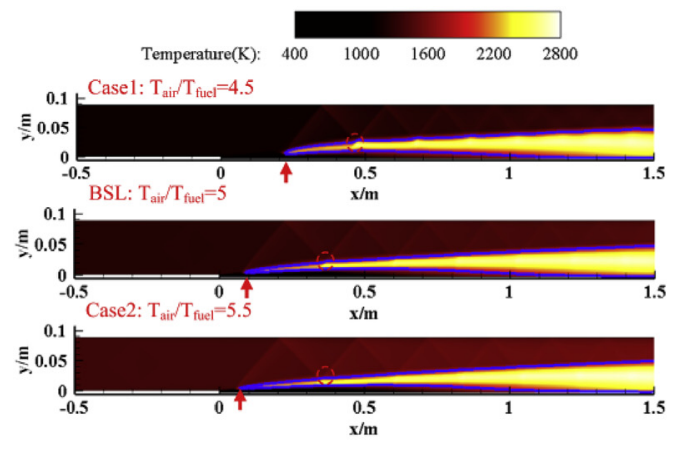

(a)

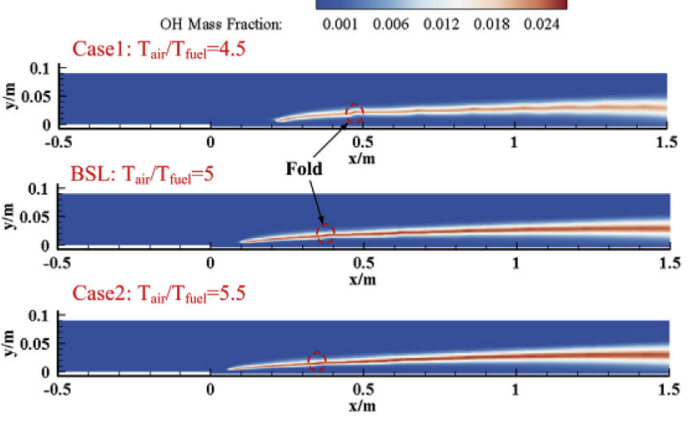

(b)

Fig. 17 - Temperature (a) and OH mass fraction (b) contours for different temperature ratios.

As labeled by red arrows in Fig. 17(a), at the origination of ignition, a shock wave is generated and the flame surface becomes wrinkled due to the pressure increase induced by shock waves. This can be better illustrated in Fig. 17(b) for $\mathrm{OH}$ mass fraction contour and the dotted circle is used to indicate the cross position between shock wave and flame. Generally, at low inflow temperature condition such as the case $\mathrm{T}_{\text {air }} /$ $\mathrm{T}_{\text {fuel }}=4.5$, the strength of the shock train is high and the flame surface produces relatively large folds at the intersection with the reflected shock waves. As the inflow temperature increases, the flame surface becomes more flat through the whole flow path and its thickness is slightly increased at the exit.

Fig. 18(a) presents distributions of the skin-friction coefficient along the bottom wall for different temperature ratios. The whole variation trends for the two cases $\mathrm{T}_{\text {air }} / \mathrm{T}_{\text {fuel }}=5$ and 5.5 are basically consistent. By observing Fig. 17(a), it could be noticed that the self-ignition and the corresponding positions of the interaction between shock train and the flame are similar for these two conditions. The formation of flame in boundary layer and the corresponding interaction between shock train and flame play a key role in skin-friction reduction.

The situation is different at the low temperature $\left(\mathrm{T}_{\text {air }} /\right.$ $\left.\mathrm{T}_{\text {fuel }}=4.5\right)$ condition. Near the fuel injector $(0<\mathrm{x}<0.2 \mathrm{~m})$, the skin-friction coefficient first decreases and then increases.
This phenomenon did not appear in the other two conditions. As no combustion occurs in this region (Fig. 17(a)), this variation of skin friction should be induced by the change of the boundary layer flow, that is, the boundary layer transition. This further proves that the turbulent model employed in this paper can well capture the process of boundary layer transition. After that, near $\mathrm{x}=0.2 \mathrm{~m}$, which is the position of selfignition for $\mathrm{T}_{\text {air }} / \mathrm{T}_{\text {fuel }}=4.5$, as illustrated for the other two cases above, the flame generation leads a rapid decline in the skin-friction coefficient, and then under the formation of the first shock wave, it rises promptly. Compared to other hightemperature cases, due to the strength of initial shock wave being high, the value of the skin-friction coefficient increases as high as 0.0015 . After that, it fluctuates along the flow path due to the interaction between shock train and flame.

Fig. 18(b) shows the distributions of the heat flux through the wall for these three cases. Basically, changes in airflow temperature do not have a large effect on the wall heat transfer. Upstream of self-ignition, where no combustion occurs, the fuel injection into boundary layer is equivalent to film cooling. Thus, the amount of heat transfer to the wall is quite small. Then as the diffusion and turbulent transport of the heat release produced by flame to the wall, the heat flux to the wall increases along the flow path.

Based on the analysis above, the characteristics of boundary layer combustion with shock train/flame 


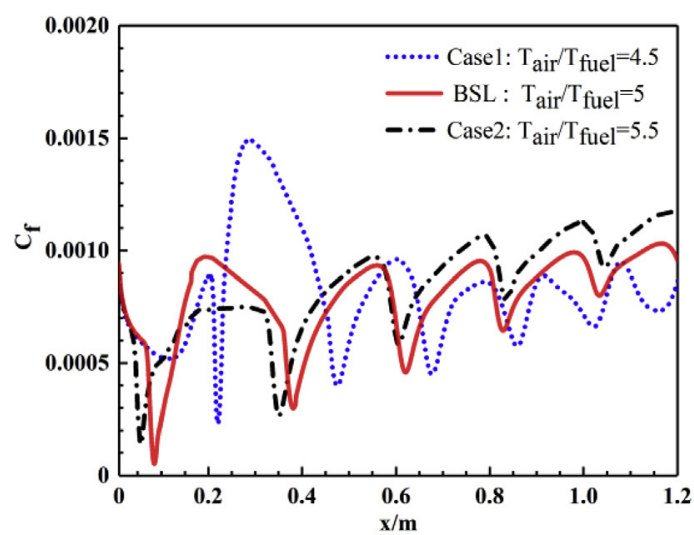

(a)

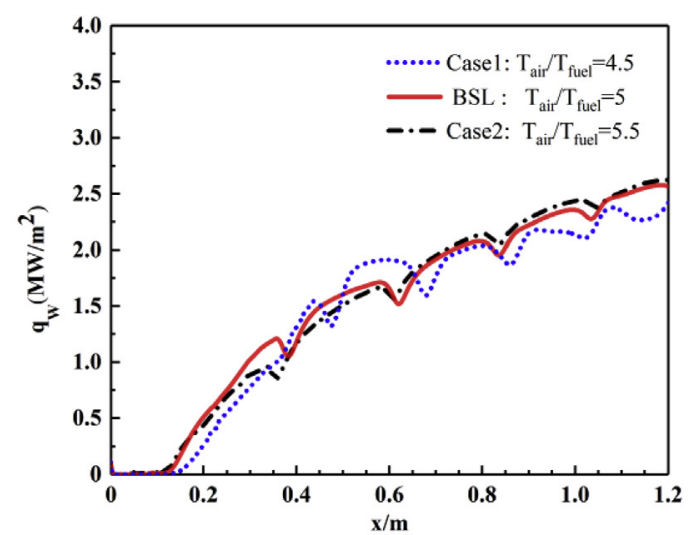

(b)

Fig. 18 - Comparisons of $C_{f}(a)$ and $q_{w}(b)$ for different temperature ratios.

interaction could be illustrated in Fig. 19. The sudden expansion of the flow area at the fuel injector step makes the airflow accelerate first and an expansion wave is generated. A mixing layer is then produced between the airflow and the hydrogen jet and at some distance downstream, hydrogen is selfignited. At higher inflow temperatures, the ignition time decreases and the self-ignition position is closer to the injector. The occurring of ignition is like a perturbation in supersonic flow, which can induce a shock wave. Then a shock train can be formed as this shock wave is reflected between the upper wall and the flame. Therefore, the heat release from combustion is the major effect on the variation of skin friction and heat transfer on the wall.

\section{Influence of $\mathrm{H}_{2} \mathrm{O}$ component variation in airflow}

Two other $\mathrm{H}_{2} \mathrm{O}$ mole fractions, $\mathrm{C}_{\mathrm{H} 2 \mathrm{O}}=20.48 \%$ and $30.72 \%$, are selected to investigate the effect of water component variation in airflow on boundary layer combustion. Temperature contour and the distribution of temperature at the exit for different $\mathrm{H}_{2} \mathrm{O}$ mole fractions are shown in Fig. 20. Fig. 20 (a) shows that both the shock train and the self-ignition position are not significantly altered with the variation of $\mathrm{H}_{2} \mathrm{O}$ concentration in airflow. In addition, it can be seen that both the maximum temperature and the flame thickness are slightly reduced at the exit as the $\mathrm{H}_{2} \mathrm{O}$ mole fraction increases.

Fig. 21 represents the distributions of skin-friction coefficient and heat transfer for different $\mathrm{H}_{2} \mathrm{O}$ mole fractions. As illustrated in Fig. 21, the heat release rate from the flame do not change a lot; the variation of both skin friction and heat transfer along the wall are similar for these three cases. More $\mathrm{H}_{2} \mathrm{O}$ is not of benefit for skin-friction reduction and although the specific heat capacity of water is high compared to other components in airflow, the increase of water is not conducive to the reduction of heat transfer on the wall. One possible reason is that the addition of $\mathrm{H}_{2} \mathrm{O}$ would block the mixing between oxygen and hydrogen which can restrain combustion to a certain extent. This also explains from another side that combustion in boundary layer can suppress the turbulence transportation to the wall, thereby facilitating skinfriction reduction.

\section{Influence of the air/fuel pressure ratio}

For real hypersonic flight, changes in external atmospheric pressure will have an important impact on scramjet engine performance. In this section, two other pressure ratios, $\mathrm{P}_{\text {air }} \mathrm{P}_{\text {fuel }}=0.9$ and 1.1, are selected to investigate the effect of the air/fuel pressure ratio on boundary layer combustion.

Fig. 22(a) shows the pressure contours at different air/fuel pressure ratios. Different from all the conditions studied above, for the $\mathrm{P}_{\mathrm{air}} / \mathrm{P}_{\text {fuel }}=0.9$ case, the expansion wave disappears when the airflow flows through the step. This is mainly because as the fuel jet pressure is larger than that of airflow, the expansion of the fuel jet can squeeze the airflow, which effectively reduces the influence of geometrical area expansion. Based on the analysis of the flow field structure, it can be concluded that both the temperature distribution and the

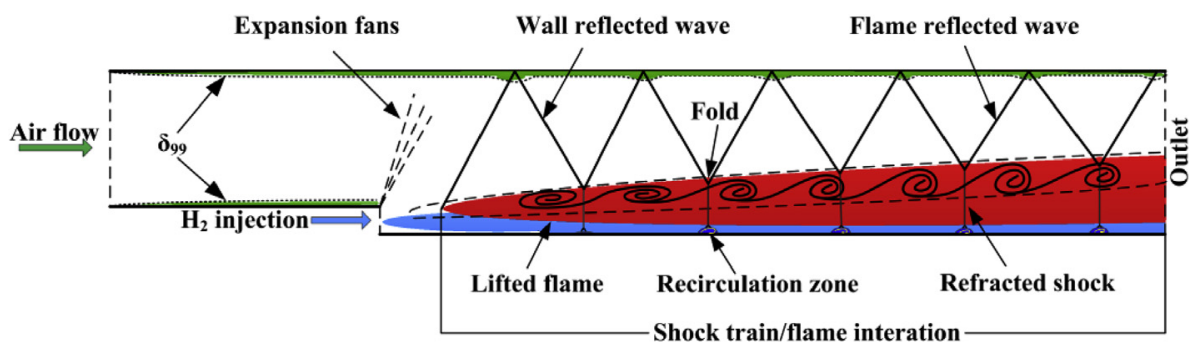

Fig. 19 - Schematic of supersonic boundary-layer combustion with shock train. 


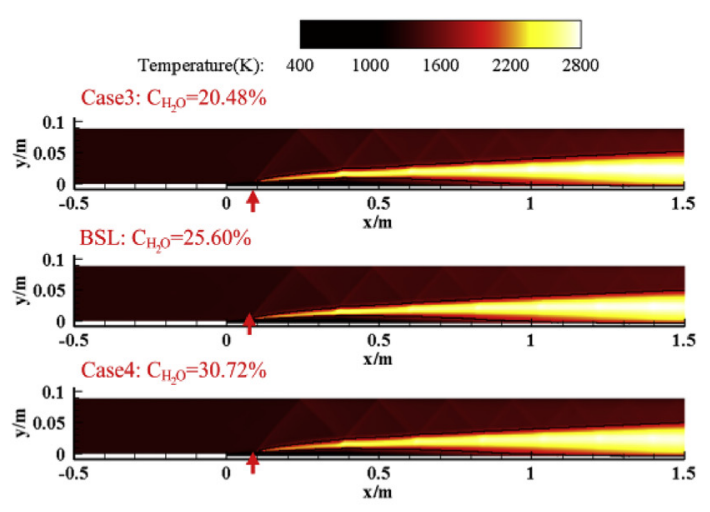

(a)

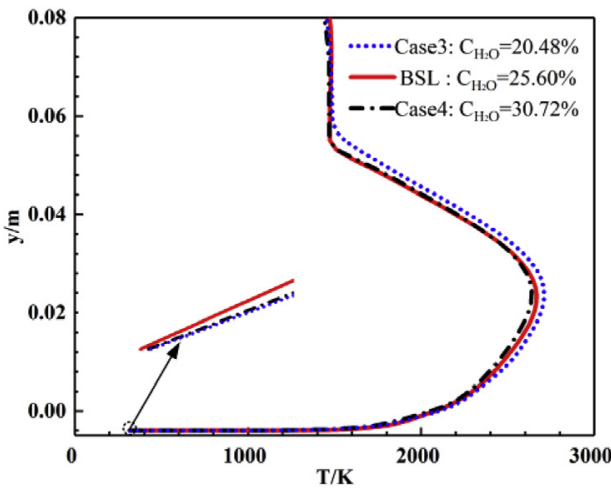

(b)

Fig. 20 - Temperature contour (a) and distribution at outlet (b) for different $\mathrm{H}_{2} \mathrm{O}$ mole fractions.

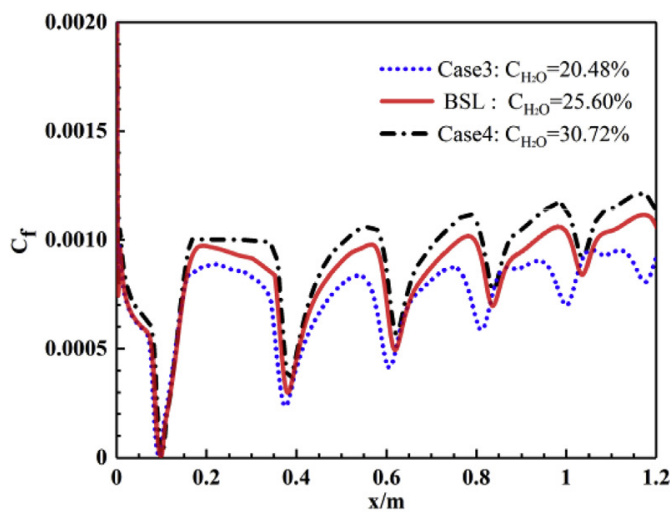

(a)

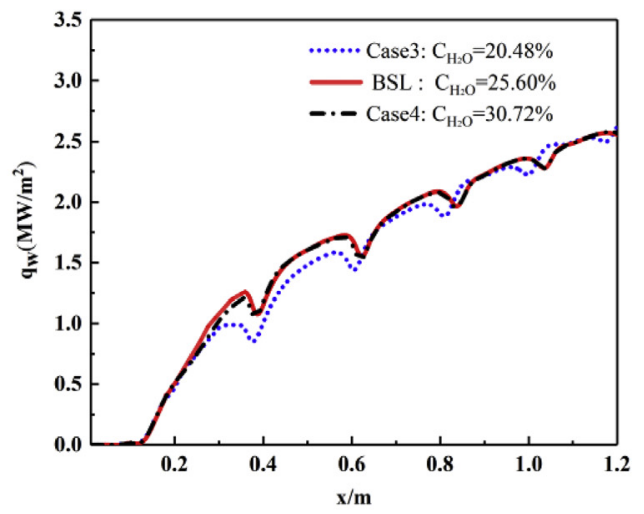

(b)

Fig. 21 - Comparisons of $C_{f}(a)$ and $q_{w}(b)$ for different $\mathrm{H}_{2} \mathrm{O}$ mole fractions.

corresponding flame structure which is represented by $\mathrm{OH}$ contour will not be largely varied at different pressure ratios. Therefore, the results for these two parameters are not presented here for brevity. Furthermore, Fig. 22(b) shows that the exit temperature profiles of perpendicular to the exit, when the hydrogen is burning in the boundary layer flows through the streamwise, static temperature of the flame rises rapidly because of the combustion heat release, which leads to the high-temperature region near the wall in the outlet.

The skin-friction coefficient and the heat transfer along the bottom wall for different pressure ratios are given in Fig. 23. It could be seen that at the upstream of self-ignition position and near its downstream $(0<x<0.4 \mathrm{~m})$, increasing the airflow pressure is of benefit for skin-friction reduction as it can
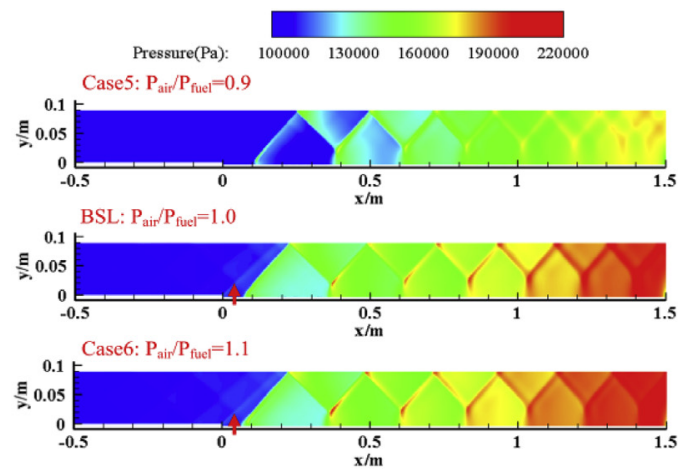

(a)

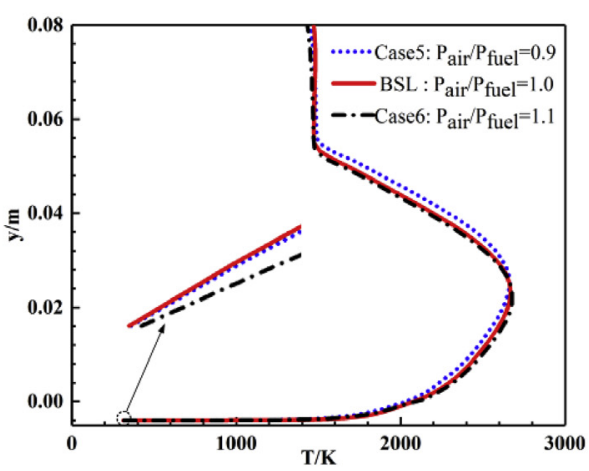

(b)

Fig. 22 - Pressure contours (a) and outlet temperature profiles (b) at different pressure ratios. 


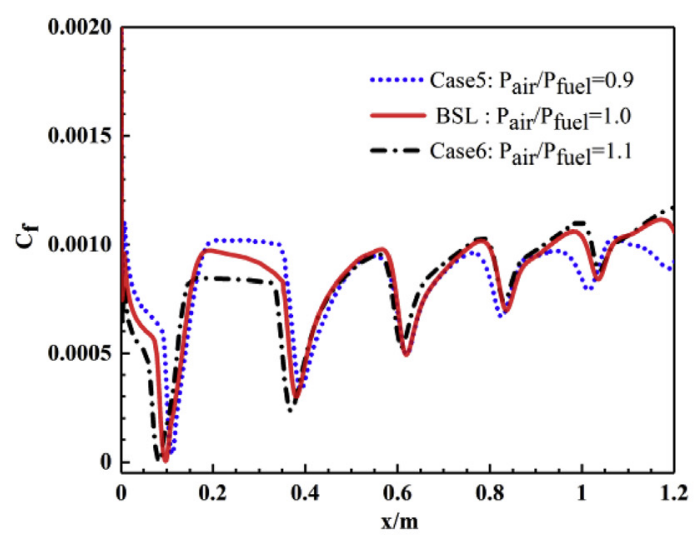

(a)

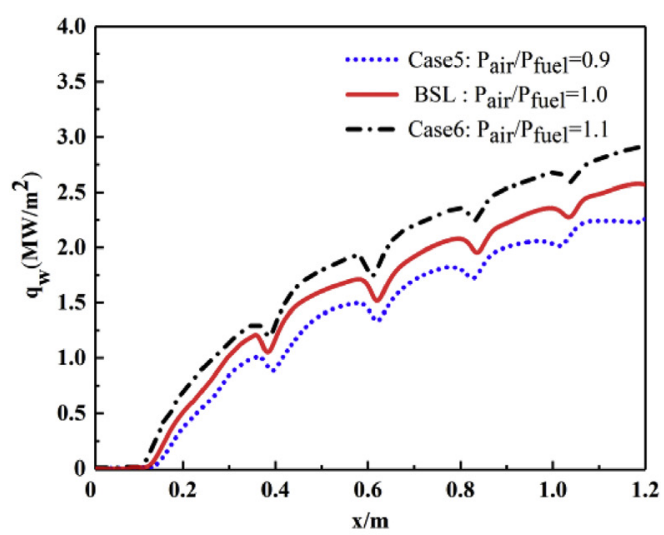

(b)

Fig. 23 - Comparisons of $C_{f}(a)$ and $q_{w}(b)$ at different pressure ratios.

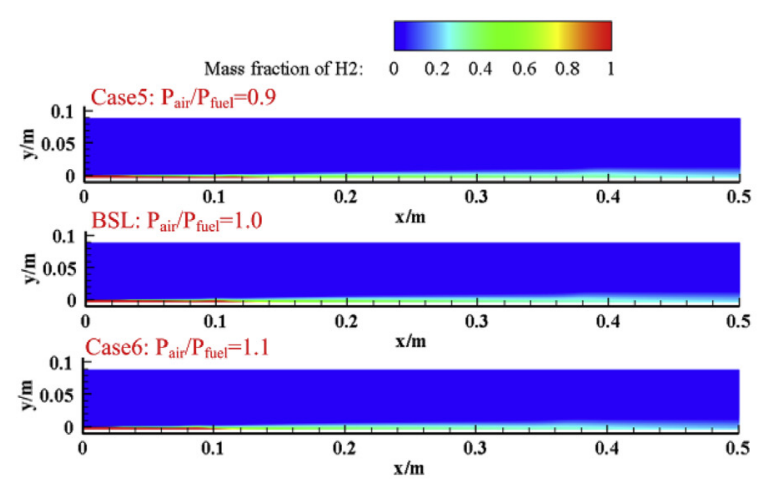

(a)

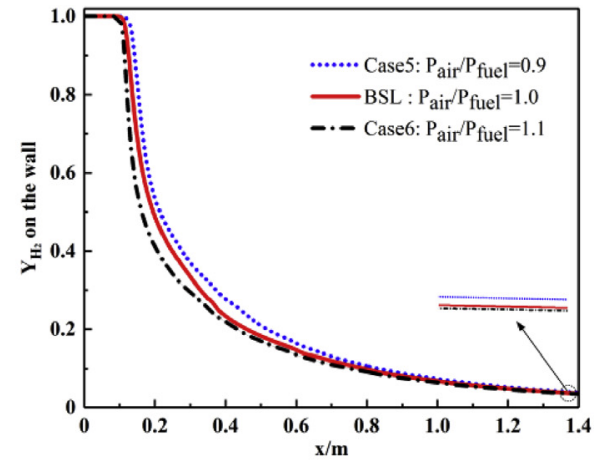

(b)

Fig. $24-\mathrm{H}_{2}$ contours (a) and $\mathrm{H}_{2}$ mass fraction along the wall (b) at different pressure ratios.

effectively reduce ignition-delay time of hydrogen, thereby promoting earlier combustion which could be illustrated by $\mathrm{H}_{2}$ mass fraction distribution in Fig. 24. Then with the turbulence mixing and heat transfer from the flame in boundary layer, the increase of boundary layer thickness becomes the dominant factor. Downstream, the decrease of airflow pressure can enhance the expansion of boundary layer, which is benefit for skin-friction reduction. Thus, near the exit, the skin friction will be decreased with the decrease of air/fuel pressure ratio.

Fig. 23(b) shows the variation of the heat flux to the wall at different pressure ratios. With the increase of airflow pressure, the heat flux to the wall is enhanced. This is mainly because the alteration in airflow pressure can cause the distance between the flame surface and the wall to change. High airflow pressure brings the flame be closer to the wall, which in turn leads to an increase in the heat transfer to the wall.

\section{Conclusions}

In the present study, the mechanism of the skin-friction reduction by boundary layer combustion is investigated with Transition $k-k l-w$ model. At the same time, the influences of different inlet boundary conditions on boundary layer combustion have been evaluated. The useful conclusions can be drawn as follows:

1) The numerical results show that the Transition $k-k l-w$ model can adequately deal with the boundary layer combustion based on existing experimental data. By comparing to the pure-mixing condition, it shows boundary layer combustion is an effective way for reducing skin friction in supersonic flows and it does not have a drastic effect on wall heat transfer. The wall friction resistance could be reduced as large as 50\% through boundary layer combustion while pure-mixing can only bring about $10 \%$ drag reduction. Heat release in boundary layer leads to the reducing in density and the thickening of the boundary layer. Thus, the velocity gradient normal to the wall and the corresponding skin friction could be reduced.

2) For the flow field structure, a lifted non-premixed flame is formed in boundary layer and a shock wave is generated since the origination of ignition. This shock wave is then continuously reflected between the upper wall and the flame, creating a shock train. When the shock waves intersect the flame surface, it can make the flame surface become wrinkled. In addition, except for reflection, the shock wave is also refracted inside the flame to the wall, 
which will influence both the skin friction and heat transfer on the wall.

3) As the temperature increases, both the skin friction and heat transfer increase, and the self-ignition position moves upstream. When the airflow temperature is low, as the distance between the fuel outlet and the self-ignition position is long enough, the boundary layer transition occurs, which can make an increase of skin friction upstream the flame. The flame generation leads a rapid decline in skin friction, and then under the interaction between the shock wave and the flame, the skin friction rises promptly.

4) The self-ignition position and the corresponding flame structure are not significantly altered at different water contents in the airflow. As the addition of $\mathrm{H}_{2} \mathrm{O}$ can restrain the mixing and combustion between oxygen and hydrogen, further skin-friction reduction can not be achieved as more $\mathrm{H}_{2} \mathrm{O}$ in airflow while the heat transfer along the wall seems similar with the variation of $\mathrm{H}_{2} \mathrm{O}$.

5) When the airflow pressure is less than that of fuel jet, the expansion of the fuel jet can squeeze the airflow, which can reduce the influence of geometrical area expansion and the expansion wave disappears at the step. Upstream the ignition location, where the influence of combustion heat release can be ignored, the increase of airflow pressure will effectively reduce ignition-delay time of hydrogen, thereby promoting earlier combustion in boundary layer. However, high airflow pressure also makes the flame be more adjacent to the wall, which in turn leads to an increase in wall heat transfer.

\section{Funding}

This work has been supported by the National Natural Science Foundation of China (Grant No. 51706170), China Postdoctoral Science Foundation (Grant No. 2019TQ0246, 2019M663734), the Foundation of State Key Laboratory of Coal Combustion (FSKLCCA2004), the Natural Science Basic Research Program of Shaanxi (Program No.2020JQ-007), Foundation of State Key Laboratory of High Temperature Gas Dynamics, Foundation of State Key Laboratory of Turbulence \& Complex Systems, and Fundamental Research Funds for the Central Universities (Grant No. xzy012019053, xjh012019033).

\section{R E F E R E N C E S}

[1] Fry RS. A century of ramjet propulsion technology evolution. J Propul Power 2004;20(1):27-58.

[2] Anderson JD. Hypersonic and high-temperature gas Dynamics. 2nd ed. American Institute of Aeronautics and Astronautics; 2006.

[3] Paull A, Stalker RJ, Mee DJ. Experiments on supersonic combustion ramjet propulsion in a shock tunnel. J Fluid Mech 1995;296:159-83.

[4] Guo J, Geng XG, Gao P, Ou XL. Recent development of drag reduction technologies via boundary layer control. Torpedo Technol 2008;16(1):1-6.
[5] Yang HW, Gao G. Experimental study for turbulent drag reduction using A novel boundary control technique. Acta Aeronautica Astronautica Sinica 1997;18(4):455-7.

[6] Xu Z, Xu Y, Wang L, Xu WJ. Drag reduction effect of dimple concave surface in air. Tribology 2009;6:579-83.

[7] Zhang C, Qin J, Yang QC, Zhang SL, Bao W. Design and heat transfer characteristics analysis of combined active and passive thermal protection system for hydrogen fueled scramjet. Int J Hydrogen Energy 2015;40(1):675-82.

[8] Sun Z. Progress in plasma assisted drag reduction technology. Advances in Mechan 2003;33(1):87-94.

[9] Luo J, Xu M, Dai W, Liu Z. Numerical simulation investigation on plasma injection for drag reduction of hypersonic vehicle. J. Astronaut 2009;30(1):120-3.

[10] Karaca M, Zhao S, Fedioun I, Lardjane N. Implicit large eddy simulation of vitiation effects in supersonic air/H2 combustion. Aero Sci Technol 2019;89:89-99.

[11] Choubey G, Pandey KM. Effect of variation of inlet boundary conditions on the combustion flow-field of a typical double cavity scramjet combustor. Int J Hydrogen Energy 2018;43(16):8139-51.

[12] Satheesh K, Jagadeesh G. Effect of electric arc discharge on hypersonic blunt body drag. Shock Waves 2009:577-82.

[13] Stalker RJ. Control of hypersonic turbulent skin-friction by boundary-layer combustion of hydrogen. J Spacecraft Rockets 2005;42(4):577-87.

[14] Chan WYK, Mee DJ, Smart MK, Turner JC, Stalker RJ. Boundary layer combustion for viscous drag reduction in practical scramjet configurations. In: 27th international congress of the aeronautical sciences. France: Nice; 2010. p. 19-24.

[15] Larin O, Levin V. Flow in a turbulent supersonic boundary layer with a heat source. Tech Phys Lett 1999;25(4):265-6.

[16] Levin V, Larin O. Skin-friction reduction by energy addition into a turbulent boundary layer. In: AIAA paper 2003-0036; 2003.

[17] Burtschell Y, Zeitoun DE. Numerical investigation of $\mathrm{H}_{2}$ injection in Mach 5 air flow with a strong shock/boundary layer interaction. Shock Waves 2004;13(6):465-72.

[18] Barth JE, Wheatley V, Smart MK. Hypersonic turbulent boundary-layer fuel injection and combustion: skin-friction reduction mechanisms. AIAA J 2013;51(9):2147-57.

[19] Clark RJ, Bade Shrestha SO. Boundary layer combustion for skin-friction drag reduction in scramjet combustors. In: AIAA paper 2014-3667; 2014.

[20] Gao ZX, Jiang CW, Pan SW. Combustion heat-release effects on supersonic compressible turbulent boundary layers. AIAA J 2015;53(7):1949-68.

[21] Edwards JR, Boles JA, Baurle RA. Large-eddy/Reynoldsaveraged Navier-Stokes simulation of a supersonic reacting wall jet. Combust Flame 2012;159(3):1127-38.

[22] Burrows MC, Kurkov AP. An analytical and experimental study of supersonic combustion of hydrogen in vitiated air stream. AIAA J 1973;11(9):1217-8.

[23] Burrows MC, Kurkov AP. Supersonic combustion of hydrogen in a vitiated air stream using stepped wall injection. In: AIAA paper 71-721; 1971.

[24] Denman AW. Large-eddy simulation of compressible turbulent boundary layers with heat addition. Ph.D. Thesis. Queensland, Australia: Univ. of Queensland; 2007.

[25] Liu H, Gao ZX, Tang YH, Jiang C, Lee CH. Improvement of skin friction and heat transfer prediction theory of turbulent boundary-layer combustion of hydrogen. Int J Hydrogen Energy 2017;42(41):26123-31.

[26] Zhang P, Xu JL, Yu Y, Cui W. Effect of adverse pressure gradient on supersonic compressible boundary layer combustion. Aero Sci Technol 2019;88:380-94. 
[27] Marinov NM, Westbrook CK, Pitz WJ. Detailed and global chemical kinetics model for hydrogen. In: 8th international symposium on transport processes. SF, U.S.A; 1995.

[28] Huang ZW, He GQ Qin F, Wei XG. Large eddy simulation of strut enhanced mixing for supersonic combustion. J Solid Rocket Technol 2015;38(5):664-70.

[29] Liou MS, Steffen CJ. A new flux splitting scheme. J Comput Phys 1993;107(1):23-39.

[30] Van LB. Toward the ultimate conservative difference scheme. IV. A second order sequel to godunov's method. J Comput Phys 1979;32:101-36.

[31] Keistler PG, Gaffney RL, Xiao X, Hassan HA. Turbulence modeling for scramjet applications. In: AIAA paper 20055382; 2005.

[32] Engblom WA, Frate FC, Nelson CC. Progress in validation of wind-US for ramjet/scramjet combustion. In: AIAA paper 2005-1000; 2005.
[33] Deepu M, Gokhale S, Jayaraj S. Numerical simulation of supersonic combustion using unstructured point implicit finite volume method. J Combust Soc Jpn 2006;48(144):187-97.

[34] Brinckman KW, Calhoon WH, Dash SM. Scalar fluctuation modeling for high-speed aeropropulsive flows. AIAA J 2007;45(5):1036-46.

[35] Ebrahimi HB. CFD validation for scramjet combustor and nozzle flows. In: AIAA paper 1993-1840; 1993.

[36] Seleznev RK, Surzhikov ST, Shang JS. A review of the scramjet experimental data base. Prog Aero Sci 2019;106:43-70.

[37] Suraweera M, Mee DJ, Stalker RJ. Skin friction reduction in hypersonic turbulent flows by boundary-layer combustion. In: AIAA paper 2005-0613; 2005. 